\title{
Wagner mit neugestaltetem Technologiezentrum
}

W agner hat sein 1500 Quadratmeter großes Technikum am Standort Markdorf umfassend neu gestaltet und mit einem breiten Spektrum zukunftsweisender Beschichtungstechnologie für die unterschiedlichsten Applikationsfelder ausgestattet. Direkt nebeneinander befinden sich die Technika für die Beschichtung mit Pulverund Nasslack, in denen acht Spezialisten ihr Know-how einbringen, um die jeweils beste Applikationslösung für die Werkstücke der Kunden zu bestimmen. Ist sowohl Pulver- als auch Nasslackbeschichtung an einem Werkstück gefragt - wie zum Beispiel bei Aluminium- oder Stahlrädern - kann der Kunde jeden einzelnen Beschichtungsvorgang bis zum fertigen Rad verfolgen und begutachten.
Die Ausstattung des Pulver-Technikums reicht von der einzelnen Handanlage über Schnellfarbwechselanlagen bis hin zu kundenspezifischen Mehrfachachstechnologien sowie komplexen vollautomatischen Beschichtungsanlagen inklusive Beschichtungsrobotern. Zum Einsatz kommen dabei die neueste Applikations- und Steuerungstechnologie, Kabinen, Zyklone sowie Nachfilter.

Ebenso breit ist die Palette an Möglichkeiten im Nasslack-Technikum. Zur Verfügung stehen hier eine Räderbeschichtungslinie, eine Automatikbeschichtungslinie, eine Roboterkabine und ein Handapplikationsbereich mit den entsprechenden Komponenten. Alle Nasslackapplikationen können sowohl konventionell als auch elektrostatisch am Werkstück getestet werden.
In beiden Technika wurden darüber hinaus moderne Besprechungsräume eingerichtet. Damit eignet sich das Technologiezentrum nicht nur für Beschichtungsversuche für Kunden und Interessenten, sondern auch für Produktschulungen und Beschichtungsseminare. Das Team der Anwendungstechniker ist zugleich Kompetenzstelle und Ansprechpartner für anwendungstechnische Fragen der weltweiten Wagner-Organisation. Das anwendungstechnische Know-how fließt bei Wagner auch in die Ausbildung von Verfahrensmechanikern für Beschichtungstechnik mit ein, die in den vergangenen Jahren mit bundesweiten Bestnoten belohnt wurden. Insgesamt betreibt die Wagner-Gruppe sieben Technologiezentren weltweit.

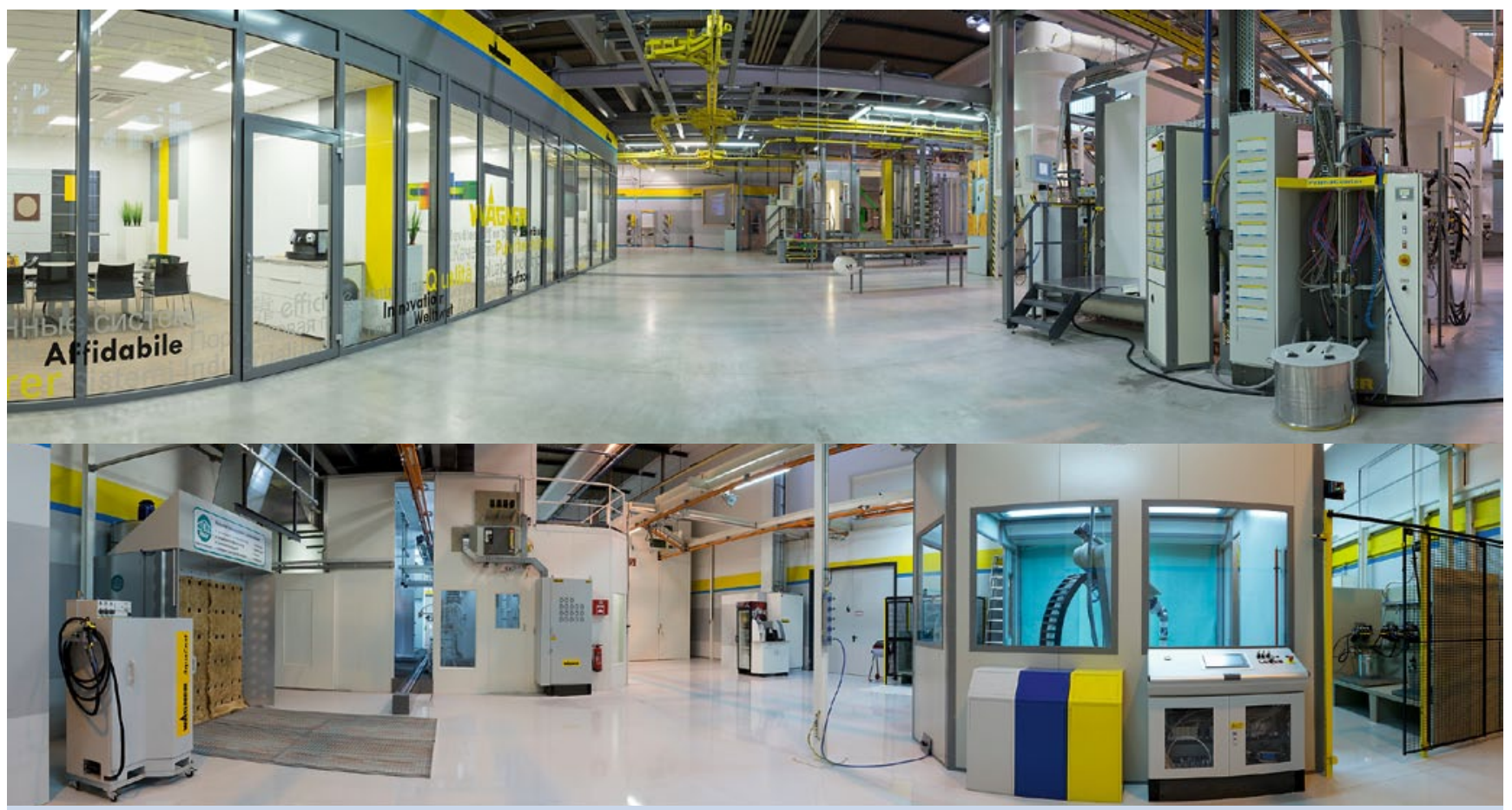

Die neuen Technika von Wagner für die Pulverbeschichtung (oben) und Nasslackierung (unten)

\section{Brillux erweitert Schnell-Lieferservice}

Drillux Industrielack hat seinen DSchnell-Lieferservice auf zukunftsorientierte Pulverlacke wie zum Beispiel Niedrigtemperatur-, Dünnschichtund Hochwetterfest-Systeme ausgeweitet. Mit 15 zusätzlichen Pulverlacksorten und 94 Einzelartikeln in ausgewählten RAL-Classic-Farbtönen bietet Brillux Industrielack nun noch mehr Flexibilität bei der Wahl der passenden Pulverlackqualität. Dabei kann aus verschiedenen Oberflächen in glatt und strukturiert so- wie aus verschiedenen Glanzgraden je Produktreihe gewählt werden. Die Lieferung erfolgt just in time. Verarbeiter können somit flexibler auf Kundenaufträge reagieren und ihre Lagerkapazitäten reduzieren. 